\title{
Evaluation of Retinal and Optic Disc Vascular Structures in Patients With Familial Mediterranean Fever (Fmf) via Optic Coherence Tomography Angiography
}

Mehmet Bulut ( $\sim$ bulutme73@yahoo.com )

Antalya training and research hospital https://orcid.org/0000-0001-8619-8078

Oznur Kutluk

Antalya Training and Research Hospital: Antalya Egitim ve Arastirma Hastanesi

Birumut Gedik

Antalya Serik State Hospital

Ulku Ucar

Antalya Training and Research Hospital: Antalya Egitim ve Arastirma Hastanesi

Yigit Caglar Bozdogan

Antalya Training and Research Hospital: Antalya Egitim ve Arastirma Hastanesi

Muhammet Huseyin Sari

Antalya Training and Research Hospital: Antalya Egitim ve Arastirma Hastanesi

Hasan Fatih Cay

Antalya Training and Research Hospital: Antalya Egitim ve Arastirma Hastanesi

\section{Research Article}

Keywords: Familial Mediterranean Fever, optic coherence tomography angiography, retinal thickness, retinal vascular density

Posted Date: January 24th, 2022

DOI: https://doi.org/10.21203/rs.3.rs-1265836/v1

License: (c) (1) This work is licensed under a Creative Commons Attribution 4.0 International License. Read Full License 


\section{Abstract}

\section{Introduction}

Familial Mediterranean Fever (FMF) is an auto-immune disease characterized by fever and serositis. With this study, we aimed at comparing the retinal vascular structures of FMF patients and healthy individuals using optic coherence tomography angiography (OCTA) device.

\section{Material and Method}

69 patients with FMF and 52 healthy controls who were matched by age and sex, didn't have any comorbidities and were admitted to our clinic for routine ophthalmic examination were enrolled in the study. 69 eyes of 69 patients and 52 eyes of 52 healthy controls that were not disqualified due to the exclusion criteria were included in the study. OCTA images of the patients and controls were analyzed.

\section{Results}

The mean age of 69 FMF patients included in the study was 39,86 $\pm 13,16.24$ were female and 16 were male. Total vascular density of deep capillary plexus (DCP) and vascular density of DCP parafovea of the FMF patients were found to be statistically significantly lower than those of the controls $(p=0,045$, $p=0,034$, respectively), while total retinal parafoveal thickness, total retinal perifoveal thickness, outer retinal parafoveal thickness and outer retinal perifoveal thickness were statistically significantly higher in the patient group compared with the control group ( $p=0,012, p=0,014, p=0,013, p=0,009$, respectively).

\section{Conclusion}

We think that the lower values of retinal vascular density in FMF patients compared with the control group were due to vascular injury caused by primarily inflammation and amyloidosis. Furthermore, it can also be suggested that inflammation had an impact on higher retinal thicknesses in FMF patients.

\section{Introduction}

Familial Mediterranean Fever (FMF) is an auto-immune disease characterized by recurrent episodes of fever and serositis [1]. It is a common disease in Turkey and its prevalence ranges from 1/400 to 1/1000 while the prevalence of its carriers has been reported to be 20\% [2]. The MEFV (MEditerranean FeVer) gene associated with FMF is located on the short arm of chromosome 16 (16p13.3) and encodes a 781 aminoacid protein. A chronic inflammation occurs due to abnormal pyrin synthesis caused by the mutations in this gene [3].

Although eye involvement is rare in FMF; anterior uveitis, episcleritis, posterior scleritis, frosted branch angitis and ocular surface abnormalities may occur [4-7]. 
Optic coherence tomography angiography (OCTA) is a non-invasive imaging method that has been recently used for imaging the retinal vascular blood flow. OCTA can detect motion contrast in blood flow and evaluate both superficial and deep vascular density at macular capillary plexus [8]. Previous studies detected changes in retinal vascular blood flow in FMF patients through OCTA $[9,10]$.

FMF is an inflammatory disease that may have vascular involvement. The vascular etiology of the disease could still not be explained. We think that there may be changes in the posterior segment structures and posterior segment vascular density in FMF patients which can be detected through OCTA and these results may contribute to explain the vascular pathology caused by the disease. The purpose of this study was to compare the retinal vascular structures of FMF patients and healthy individuals.

\section{Material And Method Patient Selection}

We enrolled 74 clinically diagnosed FMF patients who were followed by the Physical Therapy and Rehabilitation/Rheumatology Clinic of Antalya Training and Research Hospital at Health Sciences University. A total of 52 age and sex matched healthy individuals who had no comorbidities were chosen as the control group among patients who admitted to Ophthalmologic Diseases Clinic of the same hospital for routine ophthalmic examination. Among FMF group, a total of 5 patients were excluded due to having exclusion criteria (3 of them had a refractive error greater than 3 diopters, 1 had a history of previous refractive surgery and 1 had dry age macular degeneration). As a result, 69 eyes of $69 \mathrm{FMF}$ patients and 52 eyes of 52 healthy controls were evaluated ophthalmologically.

Exclusion criteria were as follows: having another pathology but FMF (e.g. glaucoma, uveitis, macular degeneration, diabetic retinopathy, amblyopia, epiretinal membrane), refractive error above \pm 3 diopters, axial length greater than $24 \mathrm{~mm}$ and lower than $21 \mathrm{~mm}$, history of ophthalmic surgery except cataract surgery without complications 1 year before, systemic diseases.

The demographic characteristics of the patients and controls (age, sex, drugs they were taking, systemic diseases etc.) as well as examination results were available in their files. The time from the onset of complaints to admission and follow-up time at our clinic were analysed. The data from the previous MEFV gene analysis were obtained from the patients' past medical records if present. The results of complete ophthalmologic examination, biomicroscopic and fundus examination of the patients and controls were assessed. OCTA images of the patients and controls were analyzed. For OCTA imaging, "Spectral-domain OCTA" (AngioVue; Optovue, Inc, Fremont, CA) device was used.

\section{OCTA Evaluation}

OCTA measurement of the patient was performed at $6 \times 6 \mathrm{~mm} \mathrm{HD}$ angio retina and $4,5 \times 4,5 \mathrm{~mm}$ angio disc scans. Images with poor quality due to motion artefact and other artefacts were not included in the 
study. Images with a signal quality greater than $8 / 10$ were assessed.

Foveal vascular density (FVD) was recorded as \% of the vascular density in $1 \mathrm{~mm}$-diameter circle centered on fovea, parafoveal vascular density (PAFVD) was recorded as $\%$ of the vascular density in the circle from $1 \mathrm{~mm}$ to $3 \mathrm{~mm}$, perifoveal vascular density (PEFVD) was recorded as \% of the vascular density in the ring from $3 \mathrm{~mm}$ to $6 \mathrm{~mm}$ and the total vascular density (TVD) was recorded as \% of vascular density in $6 \mathrm{~mm}$-diameter circle centered on fovea (Figure 1).

These areas provided the cross-sectional density measurement of the superficial capillary area in automated mode. The ratio of the vascular image in these areas (white areas) to the whole area provides the percentage of density.

Foveal avascular zone (FAZ) was automatically calculated by the device, outer retinal flow (ORF) and chroiocapillaris flow (CCF) automatically determined by the device were recorded as flow in $\mathrm{mm} 2$ in the area with a central radius of $1 \mathrm{~mm}$ and area of $3.142 \mathrm{~mm} 2$.

Optic disc vascular density: The vascular density in 4,5 mm-diameter circle centered on the optic disc was recorded as \%. Retinal nerve fiber thickness (RNFL) was measured and recorded automatically by the device on 3,4 mm-diameter scanning circle centered on the optic disc.

Retinal thickness: The retinal thickness between ILM and RPE in foveal, parafoveal and perifoveal zones were automatically measured and recorded by the device (Figure 2).

Choroidal thickness: 2 different observers measured the subfoveal zone at "Enhanced HD line" crosssection. The average of values measured by the 2 observers was calculated. The RPE and sclerachoroidal junction was the border of subfloveal choroidal thickness.

\section{Statistical Analysis}

Descriptive statistics were presented as frequency, percentage, mean, standard deviation, minimum and maximum values. Assumption of normality was checked with Shapiro Wilk Test. For the analysis of the difference between the numerical values of two groups; Independent Samples $t$ test was used when data was consistent with the normal distribution while Mann-Whitney $U$ Test was used when it was not consistent. The associations between the numerical values were assessed with non-parametric Spearman Correlation Test. The analyses were performed using SPSS 23.0 software. $p<0,05$ was considered as statistically significant.

\section{Results}

The FMF group was composed of 69 patients (49 females; 71\%); the mean age of the group was 39,86 \pm 13,16 years. (Table 1) A total of 59 MEFV gene analysis results were obtained for 59 of patients, no MEFV result was found for remaining 10 patients. The most frequently encountered allele was M694V ( $n=27)$; 
other less frequent allelles were as follows: (E148Q: 15; V726A:6, M80I: 5; R202Q: 1; K695R: 1 ). The MEFV analysis was negative for 4 of subjects. All FMF patients included in the study were in remission under colchicine treatment.

Table 1

Demographic and clinical characteristics of FMF patients and controls

\begin{tabular}{|llll|}
\hline Parameters & FMF $(\mathbf{n = 6 9})$ & Control $(\mathbf{n = 5 2})$ & $\mathbf{P}$ \\
\hline Mean age (years) & $39,86 \pm 13,16$ & $40,21 \pm 12,78$ & 0,886 \\
\hline Female/Male & $49 / 20$ & $35 / 17$ & 0,661 \\
\hline Visual acuity & $20 / 20$ & $20 / 20$ & \\
\hline Disease duration (month) & $42,52 \pm 27,09$ & NA & NA \\
\hline Proteinüria (mg/dl) & $24,96 \pm 27,25$ & NA & NA \\
\hline Fibrinogene $(\mathrm{mg} / \mathrm{dl})$ & $306,79 \pm 108,42$ & NA & NA \\
\hline
\end{tabular}

Table 2 shows the comparison between the groups as regards vascular densities at superficial capillary plexus (SCP) and deep capillary plexus (DCP) of FMF patients and controls. 
Table 2

Comparatison between the groups as regards vascular densities at superficial and deep capillary plexus

\begin{tabular}{|c|c|c|c|c|c|c|}
\hline Retinal vascular density (\%) & Group & Mn. & S.D. & Min. & Max. & $\mathbf{P}$ \\
\hline SCP Total vascular & FMF & 50,51 & 3,14 & 38,1 & 54,8 & $0,987 *$ \\
\hline density & Control & 50,9 & 2,93 & 44,1 & 57,1 & \\
\hline SCP Foveal vascular & FMF & 20,18 & 6,53 & 7,6 & 32,9 & $0,495^{\star \star}$ \\
\hline Density & Control & 19,83 & 6,69 & 5,8 & 34,6 & \\
\hline \multirow[t]{2}{*}{ SCP Parafoveal vascular density } & FMF & 52,71 & 3,95 & 31,7 & 58,4 & $0,205^{\star}$ \\
\hline & Control & 53,56 & 3,21 & 44,5 & 59 & \\
\hline \multirow[t]{2}{*}{ SCP Perifoveal vascular density } & FMF & 50,9 & 3,21 & 38,2 & 55,6 & $0,915^{\star}$ \\
\hline & Control & 51,38 & 2,89 & 46,2 & 57,6 & \\
\hline \multirow[t]{2}{*}{ DCP Total vascular density } & FMF & 51,96 & 5,36 & 40,2 & 60,8 & $0,045^{*}$ \\
\hline & Control & 54,11 & 5,08 & 39,1 & 62,5 & \\
\hline \multirow[t]{2}{*}{ DCP Foveal vascular density } & FMF & 37,55 & 6,75 & 26,2 & 51,3 & $0,945^{\star \star}$ \\
\hline & Control & 37 & 7,5 & 21,7 & 48,8 & \\
\hline \multirow[t]{2}{*}{ DCP Parafoveal vascular density } & FMF & 55,82 & 3,82 & 44,2 & 63,5 & $0,034^{*}$ \\
\hline & Control & 57,13 & 4,01 & 41 & 62,3 & \\
\hline \multirow[t]{2}{*}{ DCP Perifoveal vascular density } & FMF & 53,43 & 5,89 & 38,1 & 62,8 & $0,066^{*}$ \\
\hline & Control & 55,29 & 6,19 & 32,2 & 64,4 & \\
\hline
\end{tabular}

Table 2 shows the comparison between the vascular densities at SCP and DCP of the groups. For these variables; number of patients, average, standard deviation and minimum-maximum values are presented in the table. According to Table 2, the mean DCP TVD of the FMF patients was $51,96 \pm 5,36 \%$ while mean DCP TVD of the controls was $54,11 \pm 5,08 \%$. The mean DCP PAFVD of the FMF patients was $55,82 \pm$ $3,82 \%$ while the mean DCP PAFVD of the controls was $57,13 \pm 4,01 \%$. The mean DCP TVD and mean DCP PAFVD values of the FMF patients were found to be lower than those of the control group, which was statistically significant $(p=0,045, p=0,034$, respectively).

Table 3 shows the results of comparison between the FMF patients and control group as regards their FAZ, CCF, SFCT, optic disc vascular density and retinal nerve fiber layers. 
Table 3

Comparison between the groups as regards foveal avascular zone, choriocapillaris blood flow, subfoveal choroidal thickness, optic disc vascular density and retinal nerve fiber layer.

\begin{tabular}{|c|c|c|c|c|c|c|}
\hline Variables & Group & Mn. & S.D. & Min. & Max. & $\mathbf{P}$ \\
\hline \multirow[t]{2}{*}{ Foveal avascular zone (FAZ) $\mathrm{mm}^{2}$} & FMF & 0,283 & 0,102 & 0,108 & 0,561 & $0,745^{\star}$ \\
\hline & Control & 0,282 & 0,095 & 0,062 & 0,493 & \\
\hline \multirow[t]{2}{*}{ Choriocapillaris blood flow (CCF) $\mathrm{mm}^{2}$} & FMF & 2,115 & 0,116 & 1,819 & 2,331 & 0,474 ** \\
\hline & Control & 2,099 & 0,135 & 1,582 & 2,376 & \\
\hline \multirow[t]{2}{*}{ Subfoveal choroidal thickness (SFCT) $\mu \mathrm{m}$} & FMF & 301 & 67 & 162 & 500 & $0,28 * \star$ \\
\hline & Contol & 289 & 49 & 180 & 431 & \\
\hline \multirow[t]{2}{*}{ Optic disc total vascular density (ODTVD) \% } & FMF & 56,64 & 2,57 & 49,8 & 61,2 & $0,083^{*}$ \\
\hline & Control & 56,24 & 2,18 & 49,5 & 60,8 & \\
\hline \multirow[t]{2}{*}{ Optic disc inner vascular density (ODIVD) \% } & FMF & 60,13 & 3,85 & 47,7 & 66,4 & $0,795^{\star}$ \\
\hline & Control & 60,59 & 2,87 & 51,1 & 67,4 & \\
\hline \multirow[t]{2}{*}{ Peripapillary vascular density (PPVD) \% } & FMF & 58,99 & 2,94 & 49,8 & 65,1 & $0,13^{\star}$ \\
\hline & Control & 58,55 & 2,38 & 50,1 & 63,4 & \\
\hline \multirow[t]{2}{*}{ Retinal nerve fiber layer (RNFL) $\mu \mathrm{m}$} & FMF & 113 & 13,41 & 62 & 141 & $0,952^{\star}$ \\
\hline & Control & 114 & 11,46 & 93 & 139 & \\
\hline
\end{tabular}

Table 3 shows the comparison between the groups as regards their FAZ, CCF, SFCT, optic disc vascular density and retinal nerve fiber layer. The table also includes the number of patients, mean, standard deviation and minimum-maxiimum values for these variables. According to the Table, no difference was found between the mean FAZ, CCF, SFCT, optic disc vascular density and retinal nerve fiber layer values. The mean SFCT of the FMF patients was $301 \pm 67 \mu \mathrm{m}$, while it was $289 \pm 49 \mu \mathrm{m}$ in the control group. The mean SFCT was found to be higher in the FMF patients than in the control group. This difference, however, was not statistically significant $(p=0,2 a 8)$.

Table 4 shows the comparison between the FMF patients and control group as regards their retinal thicknesses. 
Table 4

Comparison between the groups as regards their retinal thicknesses

\begin{tabular}{|lllllll|}
\hline Retinal thicknesses $(\boldsymbol{\mu m})$ & Group & Mn. & S.D. & Min. & Max. & P \\
\hline Total retinal foveal thickness (TRFT) & FMF & 253 & 17,97 & 214 & 298 & 0,508** \\
& Control & 250 & 18 & 222 & 297 & \\
\hline Total retinal parafoveal thickness (TRPAFT) & FMF & 322 & 15,77 & 256 & 353 & 0,012* \\
& Control & 316 & 11,74 & 289 & 340 & \\
\hline Total retinal perifoveal thickness (TRPEFT) & FMF & 293 & 14,05 & 244 & 325 & 0,014** \\
\hline Inner retinal foveal thickness (IRFT) & Control & 288 & 9,71 & 266 & 309 & \\
\hline Inner retinal parafoveal thickness (IRPAFT) & FMF & 70 & 10,02 & 50 & 98 & 0,89** \\
\hline Inner retinal perifoveal thickness (IRPEFT) & Control & 70 & 10,6 & 49 & 97 & \\
\hline Outer retinal foveal thickness (ORFT) & Control & 131 & 7,25 & 117 & 144 & \\
\hline Outer retinal parafoveal thickness (ORPAFT) & FMF & 116 & 6,89 & 93 & 134 & 0,264** \\
\hline Outer retinal perifoveal thickness (ORPEFT) & FMF & 176 & 10,37 & 156 & 213 & 0,013* \\
\hline Mn: Mean S.D: Standard deviation Min: Minimum Max: Maximum. *: Mann- Whitney U test; **: t-test. \\
\hline
\end{tabular}

Table 4 shows the comparison between the groups as regards their retinal thicknesses. The table also includes the number of patients, mean, standard deviation and minimum-maximum values for these variables. According to the table, among the FMF patients, the mean TRPAFT was $322 \pm 15,77 \mu \mathrm{m}$, mean TRPEFT was $293 \pm 14,05 \mu \mathrm{m}$, mean ORPAFT was $188 \pm 10,37 \mu \mathrm{m}$, mean ORPEFT was $176 \pm 9,46 \mu \mathrm{m}$; while in the control group, the mean TRPAFT was $316 \pm 11,74 \mu \mathrm{m}$, mean TRPEFT was $288 \pm 9,71 \mu \mathrm{m}$, mean ORPAFT was $184 \pm 8 \mu \mathrm{m}$, mean ORPEFT was $172 \pm 6,45 \mu \mathrm{m}$. The mean TRPAFT, mean TRPEFT, mean ORPAFT and mean ORPEFT of the FMF patients were found to be statistically significantly higher compared with the control group $(p=0,012, p=0,014, p=0,013, p=0,009$, respectively). 
Table 5

Correlations between retinal vascular density and disease duration*

\begin{tabular}{|lll|}
\hline Retinal Region & $\mathbf{r}$ & $\mathbf{P}$ \\
\hline SCP Total vascular density & $-0,246$ & 0,1 \\
\hline SCP Foveal vasculardensity & 0,152 & 0,312 \\
\hline SCP Parafoveal vascular density & $-0,217$ & 0,147 \\
\hline SCP Perifoveal vascular density & $-0,277$ & 0,062 \\
\hline DCP Total vascular density & $-0,295$ & $\mathbf{0 , 0 4 6}$ \\
\hline DCP Foveal vascular density & 0,119 & 0,43 \\
\hline DCP Parafoveal vascular density & $-0,331$ & $\mathbf{0 , 0 2 5}$ \\
\hline DCP Perifoveal vascular density & $-0,301$ & $\mathbf{0 , 0 4 2}$ \\
\hline *: Spearmen's rank correlation. & & \\
\hline
\end{tabular}

Table 5 shows the correlations between retinal vascular density and disease duration. There was a statistically significant negative correlation between the duration of FMF disease and DCP total vascular density, DCP Parafoveal vascular density, and DCP Perifoveal vascular density. Figure 3,4,5 shows these correlation graphs. No statistically significant correlation was found between FMF disease duration and other parameters.

\section{Discussion}

FMF is a common auto-inflammatory disease across the world and characterized by recurrent episodes of fever and serositis [11]. The onset age of the disease is younger than five in $2 / 3$ of patients [12]. Its clinical manifestations include high fever and pleuritic chest pain, severe abdominal pain, arthritis and serositis that may be seen as rash. The most important complication of the disease is amyloidosis and resulting organ failure that may develop $[11,13]$.

In FMF, colchicine is the standard treatment which is effective to prevent febrile attacks and amyloidosis. The incidence of amyloidosis in patients has been reported to decrease after the colchicine treatment is initiated. The most common side effects include diahhrea, nausea, rash, erythema, hair loss and elevated serum transaminase levels [14].

Ophthalmological symptoms are rare in FMF. Previous studies detected uveitis, episcleritis, posterior scleritis, frost branch angitis and ocular surface abnormalities in FMF patients [4-7]. In our study, we did not find any of these pathologies in FMF patients.

In a study, Cavdarli et al. compared the retinal vascular density, FAZ and CCF values of 38 FMF patients and 40 healthy individuals. But they did not find any statistically significant difference between the 
groups [15].

In another study, Yener et al. compared 20 FMF patients with 20 healthy individuals as regards their retinal vascular density, CCF, FAZ and RNFL, where they found that the mean temporal quadrant parafoveal vascular density of the FMF patients was higher compared with the control group, which was statistically significant; whereas the mean nasal quadrant parafoveal vascular density was found to be lower in FMF patients $(p=0,04, p=0,02$, respectively) [9].

Karaca et al. compared the retinal vascular densities of $62 \mathrm{FMF}$ patients with those of 54 healthy individuals. In their study, they found that the mean DCP inferior quadrant PAFVD and the mean DCP inferior-hemi quadrant vascular density of the FMF patients were statistically significantly lower than those of the control group $(p=0,04, p=0,03$, respectively) [10].

In our study, we found that the mean DCP TVD and mean DCP PAFVD of the FMF patients were statistically significantly lower than those of the control group $(p=0,045, p=0,034$, respectively). Also, there was a statistically significant negative correlation between the duration of FMF disease and DCP total vascular density, DCP Parafoveal vascular density, and DCP Perifoveal vascular density. FMF is an autoinflammatory disease characterized by episodes during which severe inflammation occurs in the body. At that time, proinflammatory cytokines appear [16-18]. Studies demonstrate that increased inflammation and amyloidosis during FMF episodes lead to endothelial dysfunction, atherosclerosis and platelet activation. As a consequence, pericarditis, pulmonary hypertension, coronary artery disease, cardiomyopathy and vascular diseases develop [19-21]. We think that lower vascular density in FMF patients and negative correlation between the duration of FMF disease and DCP vascular density in our study were due to vascular injury caused by inflammation and amyloidosis.

Some of the previous studies reported a difference between the FMF patients and the control group as regards their mean retinal thicknesses, SFCT and RNFL $[22,23]$. In a study, Bicer et al. found that SFCT was lower in FMF patients than in the control group [24]. Gundogan et al., however, found that SFCT of the FMF patients measured during acute attack was higher than that of the control group [25].

In our study, the mean TRPAFT, mean TRPEFT, mean ORPAFT and mean ORPEFT of the FMF patients were statistically significantly higher compared with the control group $(p=0,012, p=0,014, p=0,013$, $p=0,009$, respectively). SFCT was higher in FMF patients than in the control group, which was not, however, statistically significant $(p=0,28)$. FMF is characterized by episodes of inflammation. Cytokines that appear due to inflammation lead to increased vascular permeability and vascular dilation $[17,26$, 27]. We think that this increased retinal and choroidal thickness in FMF patients was due to inflammation.

The number of the patients was low in our study, which may be considered as a limitation. Furthermore, all FMF patients were in remission. Different results may be obtained if patients having attacks are also included in the study. 


\section{Conclusion}

In conclusion, we compared FMF patients and control group as regards their retinal and choroidial thicknesses as well as vascular structures of the retina and optic disc. We think that lower retinal vascular density in FMF patients compared with the control group was due to inflammation and amyloidosis. Moreover, it can also be suggested that inflammation had an impact on higher retinal thicknesses of FMF patients. We think that this study can provide additional contribution to studies to be performed for the clarification and early detection of the pathogenesis of FMF.

\section{Declarations}

\section{Funding}

No funding was received for conducting this study.

\section{Compliance with Ethical Standarts::}

All procedures performed in studies involving human participants were in accordance with the ethical standards of the institutional and/or national research committee and with the 1964 Helsinki declaration and its later amendments or comparable ethical standards.

\section{Ethical approval}

The study protocol was approved by the Health Sciences University Antalya Training And Research Hospital ( Date: 18.03.21 No:3/17).

\section{Conflict of interest}

All authors declare no funding was received and no conflict of interest/competing interests.

\section{Data availability}

The data supporting the findings of the study are available from the corresponding author upon request.

\section{Code availability}

Not applicable. 


\section{Authors' contributions}

All authors contributed to the study conception and design. Material preparation, data collection, and analysis were performed by MB, HFC, BG, OK and YCB. The first draft of the manuscript was written by $\mathrm{MB}, \mathrm{HFC}, \mathrm{BG}, \mathrm{YCB}$. OK, UU and MHS read, revised, and approved the final manuscript.

\section{Consent to participate}

Written consent was acquired by all participants.

\section{Consent for publication}

Written consent was acquired by all participants.

\section{References}

1. Barut K, Sahin S, Adrovic A et al (2018) Familial Mediterranean fever in childhood: a single-center experience. Rheumatol Int 38(1):67-74. https://doi.org/10.1007/s00296-017-3796-0

2. Yılmaz E, Ozen S, Balci B et al (2011) Mutation frequency of familial Mediterranean fever and evidence for a high carrier rate in the Turkish population. Eur J Hum Genet 9:553-555. https://doi.org/10.1038/sj.ejhg.5200674

3. Park YH, Wood G, Kastner DL, Chae JJ (2016) Pyrin inflammasome activation and RhoA signaling in the autoinflammatory diseases FMF and HIDS. Nat Immunol 17:914-992. https://doi.org/10.1038/ni.3457

4. Akalin T, Demirag MD, Tezcan ME et al (2010) Scleritis and sudden hearing loss associated with familial Mediterranean fever. Clin Exp Rheumatol 28:103-S114

5. Yazici A, Ozdal P, Yuksekkaya P et al (2014) Ophthalmic manifestations in familial Mediterranean fever: a case series of 6 patients. Eur J Ophthalmol 24:593-598. https://doi.org/10.5301/ejo.5000398

6. Satoh S, Itoh C, Nakamura N (2010) A case of frosted branch angiitis associated with retinal vein occlusion as a complication of familial Mediterranean fever. Nippon Ganka Gakkai Zasshi 114:621628

7. Karalezli A, Borazan M, Yilmaz S et al (2009) Conjunctival impression cytology and tear-film changes in patients with familial Mediterranean fever. Acta Ophthalmol 87:39-43. https://doi.org/10.1111/j.1755-3768.2008.01437.x

8. Gedik B, Suren S, Bulut M et al (2021) Changes in choroidal blood flow in patients with macular hole after surgery. Photodiagnosis and Photodynamic Therapy 35:102428. https://doi.org/10.1016/j.pdpdt.2021.102428 
9. Yener AU, Tayfur AC (2019) Posterior Segment Ocular Parameters in Children with Familial Mediterranean Fever. Ocular Immunology and Inflammation. https://doi.org/10.1080/09273948.2019.1695857. 18 1-6

10. Karaca EE, Ozek D, Omma A, Kemer OE (2019) Comparison of optical coherence tomography angiographyr esults of adult patients with Familial Mediterranean fever and healthy individuals. Therapeutic Advances in Ophthalmology 11:1-8. https://doi.org/10.1177/2515841419892056

11. Kisla Ekinci RMK, Balci S, Altintas DU et al (2019) The influence of concomitant disorders on disease severity of familial Mediterranean fever in children. Arch Rheumatol 33(3):282-287. https://doi.org/10.5606/ArchRheumatol.2018.6488

12. Çağlar A, Özçelik G, Akıncı N (2018) Ailevi Akdeniz Ateşi Olan Çocuklarda Genotip-Fenotip iliş̧kisi. İzmir Dr. Behçet Uz Çocuk Hast. Dergisi 8:144-150

13. Petrushkin H, Stanford M, Fortune F et al (2016) Ocul Immunol Inflamm 0:1-9. https://doi.org/10.3109/09273948.2015.1010012. Clinical Review:Familial Mediterranean Fever ; An Overview of Pathogenesis, Symptoms, Ocular Manifestations, and Treatment Clinical Review : Familial Mediterranean Fever

14. Sonmez HE, Batu ED, Ozen S (2016) Familial Mediterranean fever: current perspectives. J Inflamm Res 9:13. https://doi.org/10.2147/JIR.S91352

15. Cavdarli C, Cavdarli B, Yilmaz PT, Gultekin BP (2020) Optical coherence tomography-angiographic vascular densities in Familial Mediterranean Fever (FMF) Patients with M694V Mutations. Ophthalmic Genetics 41:257-262. https://doi.org/10.1080/13816810.2020.1759108

16. Musabak U, Sengul A, Oktenli C et al (2004) Does immune activation continue during an attack-free period in familial Mediterranean fever? Clin Exp Immunol 138:526-533. https://doi.org/10.1111/j.1365-2249.2004.02632.x

17. Yildiz M, Adrovic A, Tasdemir E et al (2020) Evaluation of co-existing diseases in children with familial Mediterranean fever. Rheumatol Int 40:57-64. https://doi.org/10.1007/s00296-019-043919.ien

18. Park YH, Remmers EF, Lee W et al (2020) Ancient familial Mediterranean fever mutations in human pyrin and resistance to Yersinia pestis. Nat Immunol 21:857-867. https://doi.org/10.1038/s41590020-0705-6

19. Ugurlu S, Seyahi E, Cetinkaya F et al (2009) Intima-media thickening in patients with familial Mediterranean fever. Rheumatology 48:911-915. https://doi.org/10.1093/rheumatology/kep131

20. Bilginer Y, Ozaltin F, Basaran C et al (2008) Evaluation of intima media thickness of the common and internal carotid arteries with inflammatory markers in familial Mediterranean fever as possible predictors for atherosclerosis. Rheumatol Int 28:1211-1216. https://doi.org/10.1007/s00296-0080605-9

21. Alsarah A, Alsara O, Laird-Fick HS (2017) Cardiac manifestations of familial Mediterranean fever. Avicenna J Med 7:158-163. https://doi.org/10.4103/ajm.AJM_78_17 
22. Alim S, Esen M, Demir AK et al (2018) Peripapillary retinal nerve fiber layer and ganglion cell-inner plexiform layer thickness in adult-onset familial Mediterranean fever. Int Ophthalmol 38:183-190. https://doi.org/10.1007/s10792-017-0446-1

23. Erdurmus M, Bekdas M, Demircioglu F et al (2014) Retinal and choroidal thickness in children with familial Mediterranean fever. Ocul Immunol Inflamm 22:444-448.

https://doi.org/10.3109/09273948.2014.916309

24. Bicer T, Celikay O, Kosker M et al (2017) Retinal and choroidal thickness in adult patients with familial Mediterranean fever. Ophthalmic Epidemiol 24:346-351. https://doi.org/10.1080/09286586.2017.1294697

25. Gundogan FC, Akay F, Uzun S et al (2016) Choroidal thickness changes in the acute attack period in patients with familial Mediterranean fever. Ophthalmologica 235:72-77. https://doi.org/10.1159/000442216

26. Ozen S, Batu ED, Demir S (2017) Familial Mediterranean Fever: Recent Developments in Pathogenesis and New Recommendations for Management. Front Immunol 8:253. https://doi.org/10.3389/fimmu.2017.00253

27. Alghamdi M (2017) Familial Mediterranean fever, review of the literature. Clin Rheumatol 36:17071713. https://doi.org/10.1007/s10067-017-3715-5

\section{Figures}




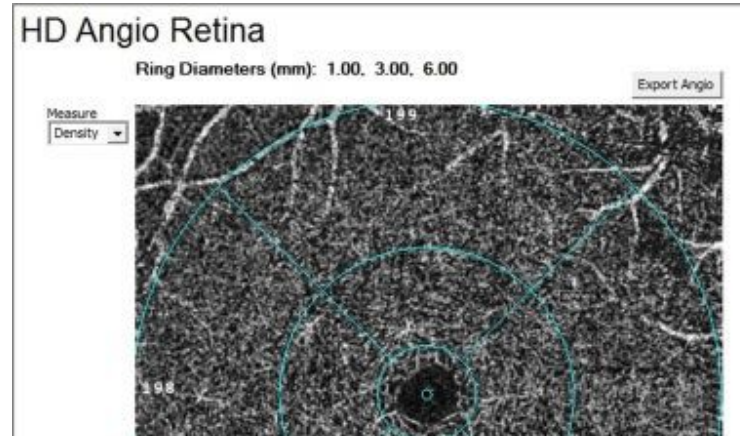

Scan Quality 9/10

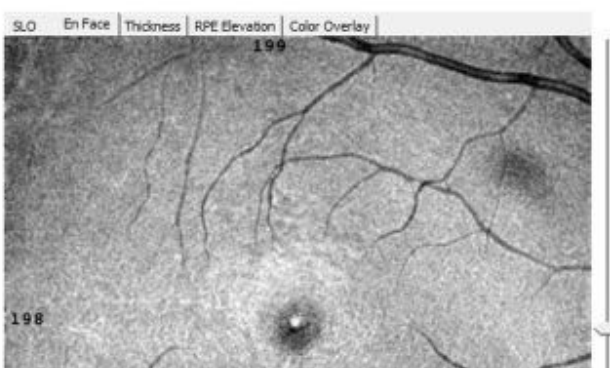

Right / OD

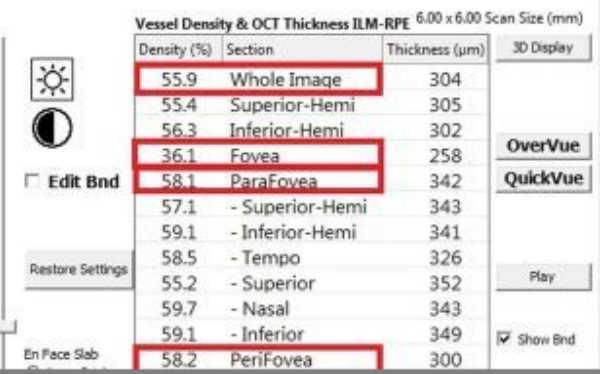

Figure 1

Vascular density values in the OCTA of an FMF patient 


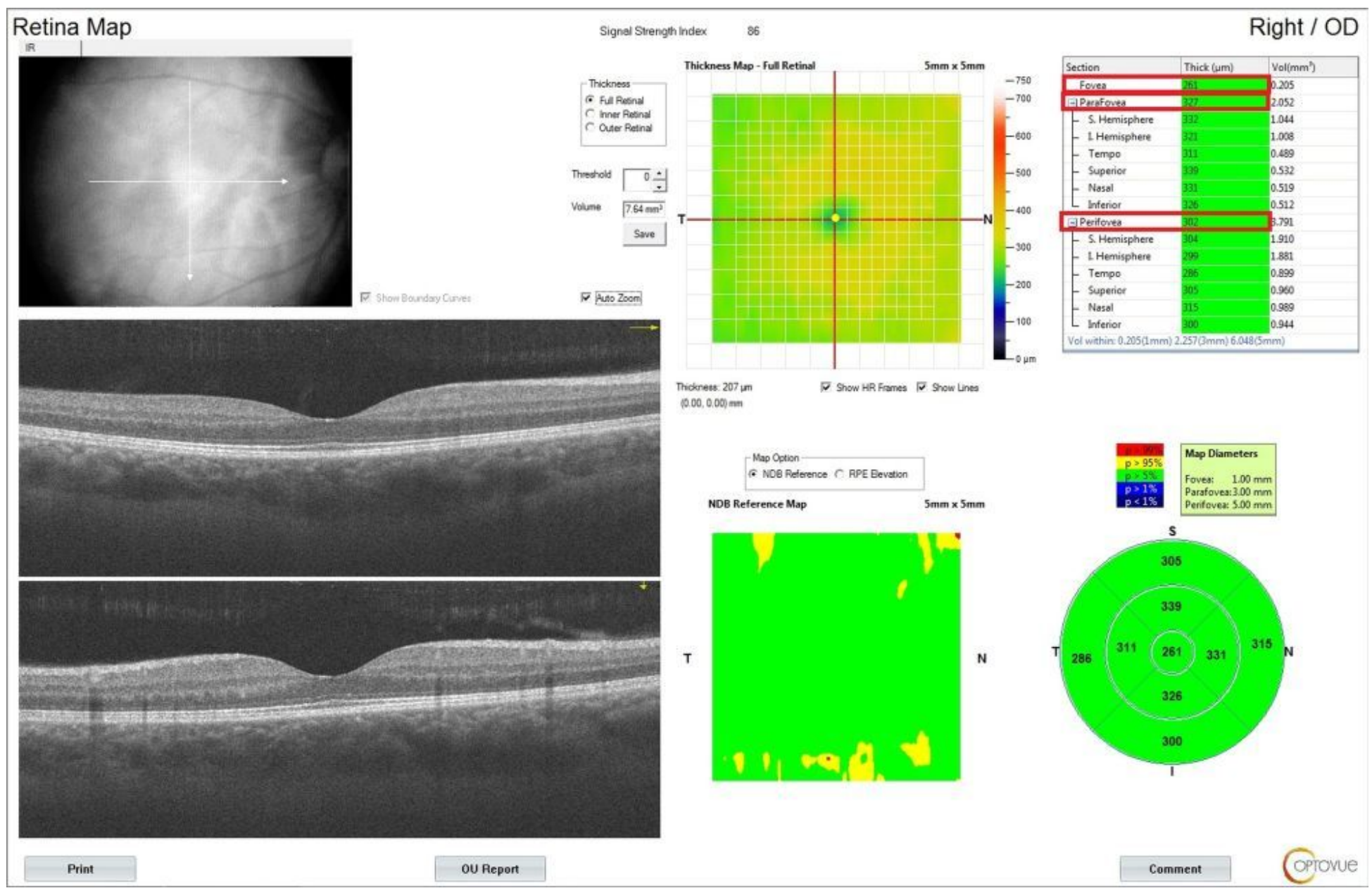

Figure 2

Retinal thickness values in the OCTA of an FMF patient 




Figure 3

Correlations between DCP (Deep capillary plexus) total vascular density and disease duration

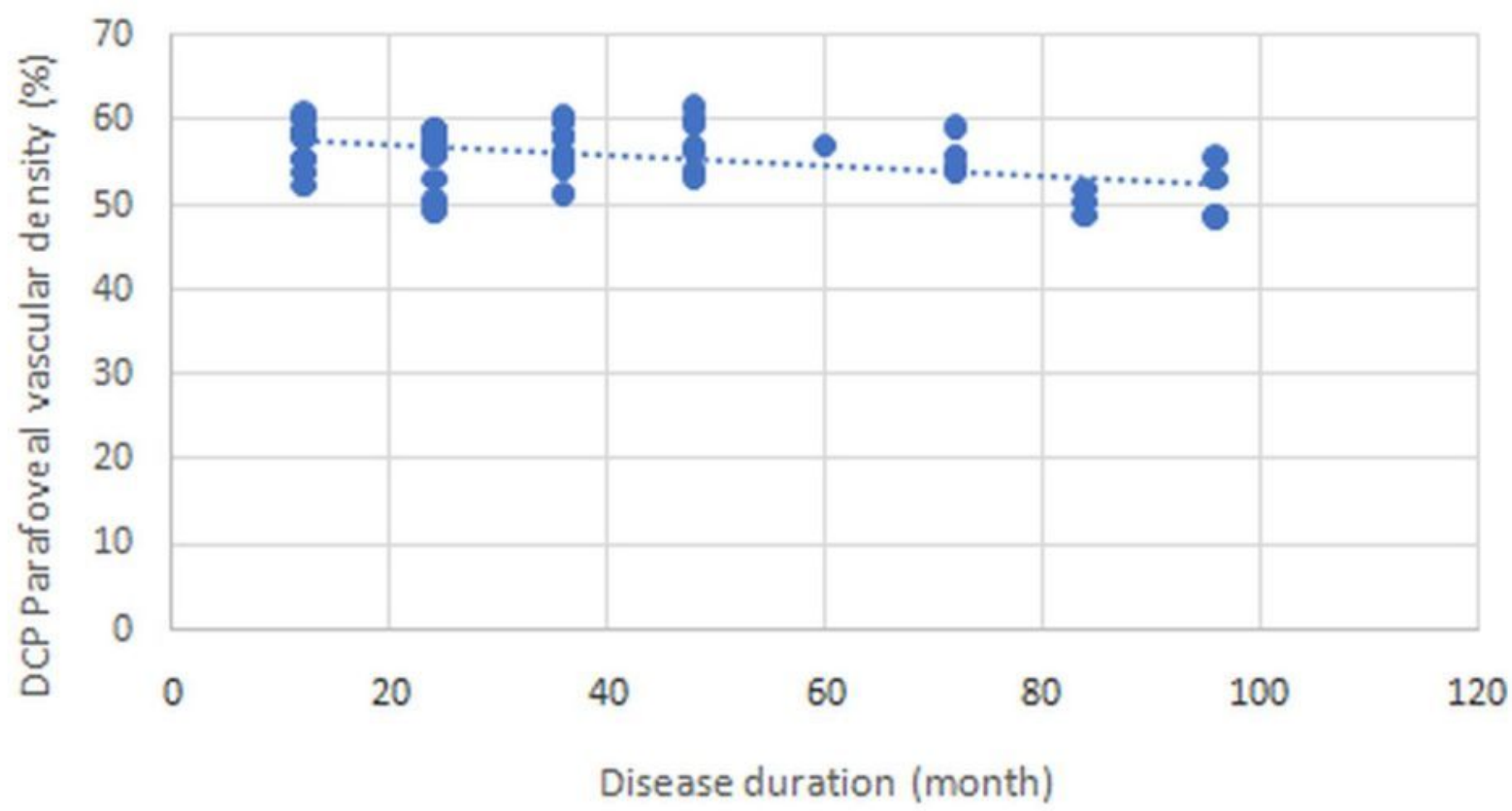

Figure 4 
Correlations between DCP (Deep capillary plexus) parafoveal vascular density and disease duration

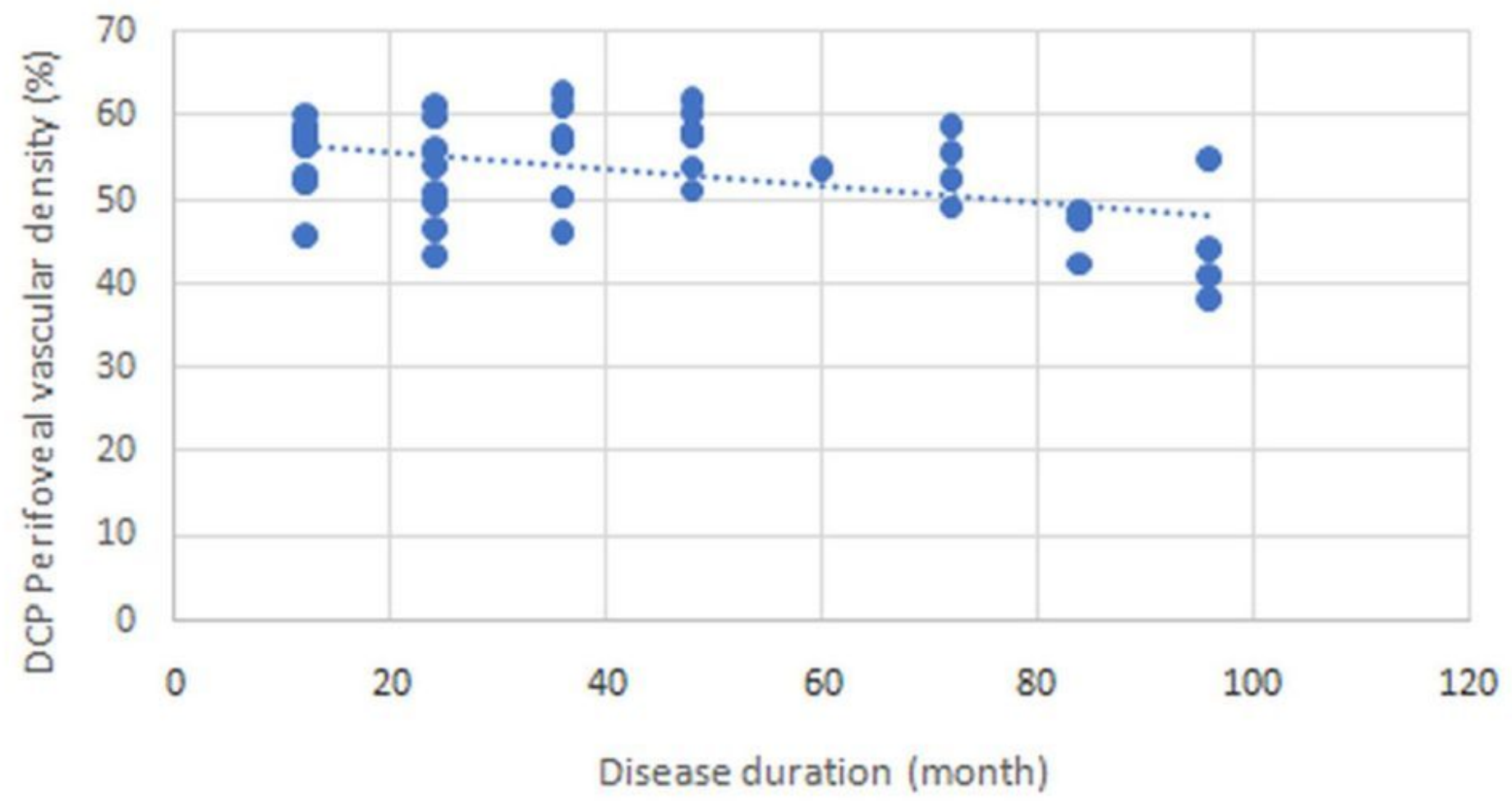

Figure 5

Correlations between DCP (Deep capillary plexus) perifoveal vascular density and disease duration 